\section{Stakeholder involvement in the innovation process: An example in medical robotics, the ROBO-K project}

\author{
Nathalie Pichot ${ }^{1}$, Kévin Nadarajah ${ }^{1}$, Isabelle Bonan², Guy \\ Caverot $^{3}$, Pauline Coignard ${ }^{4,5}$, Jean-Luc Le Guiet ${ }^{4,5}$ and Alain \\ Somat ${ }^{1 *}$
}

'Department of Psychology, University of Rennes, LP3C - EA 1285, F-35000 Rennes, France

${ }^{2}$ Physical Medicine and Rehabilitation Service, Centre Hospitalier Universitaire (CHU) de Ponchailloux, Rennes, France,

${ }^{3}$ BA Healthcare, Pacé, France

${ }^{4}$ Physical Medicine and Rehabilitation Service, Centre Mutualiste de Rééducation et Réadaptation Fonctionnelles (CMRRF) de Kerpape, Ploemeur, France

${ }^{5}$ Association APPROCHE, Siège social CMRRF de Kerpape, Ploemeur, France
Received: 23 November, 2021

Accepted: 13 December, 2021

Published: 14 December, 2021

*Corresponding author: Alain Somat, Professor, Department of Psychology, University of Rennes, France, Tel: +33-(0)6-60-53-37-16;

E-mail: alain.somat@univ-rennes2.fr

ORCID: https://orcid.org/0000-0003-1415-1777

Keywords: Technology acceptability; Stakeholder analysis; Co-construction activity; Medical robotics; Innovation process

Copyright: (c) 2021 Pichot N, et al. This is an openaccess article distributed under the terms of the Creative Commons Attribution License, which permits unrestricted use, distribution, and reproduction in any medium, provided the original author and source are credited.

https://www.peertechzpublications.com

\section{Check for updates}

\begin{abstract}
In the field of medical robotics, many studies have called for the integration of end-users in the innovation process. The objective is to identify the factors that facilitate (or not) the use of the designed robots and thus try to guarantee their diffusion in the care services. This recommendation was followed in the ROBO-K project. The ROBO-K project proposes the design and development of a mobile, interactive robot dedicated to gait rehabilitation. This project was initiated by BA Healthcare, a medical robotics company. The design of a robot was accompanied to achieve the targeted therapeutic objectives by taking into account the requirements related to the needs of the patients and the practitioners; the care activity and the institutions involved. A follow-up by the social acceptability of the technology led to focus the innovation process on a co-construction activity involving all stakeholders.
\end{abstract}

This co-construction activity was decisive, as it guided the definition of functional expectations and the technical specifications of the prototype developed. It was completed by a test phase of the prototype (in a care situation for 5 months). The results show the relevance to involve all the stakeholders in all the design and development phases of the robotic device. However, they underline the difficulties or limits linked to this type of approach in terms of innovation.

\section{Introduction}

The "innovation process" has been the subject of many theoretical proposals, the first and best known of which is the linear model of innovation. This model argues that innovation passes through four stages: Basic Research, Applied Research, Development and Production, and Diffusion [1,2]. As early as the 1960s, many authors questioned the linearity of the model, which was considered unsuitable or insufficient to grasp all the facets of innovation (e.g. [3-5]). More recently, this observation was also made by de Ana, et al. [6] when they considered 'linear' innovation processes were inappropriate for medical innovations. The authors argue that innovation in the medical field must bring together and address the opinions and needs of all stakeholders who are likely to be affected or may affect the technological device [7]. Without these prerequisites, medical technology innovations such as robotic devices may face diffusion difficulties [8].

The SIF $13^{1}$ project ROBO-K is part of this problem since 
it aims to design and develop a mobile and interactive robot dedicated to gait rehabilitation. This project was initiated by BA Healthcare, a medical robotics company focused on open innovation [9]. Aware of the difficulties associated with the implementation of an innovation process as well as the diffusion of robotized medical devices, BA Healthcare wanted to involve all stakeholders in the definition and development of the ROBO-K project. The objective was to facilitate the individual and collective appropriation of future gait rehabilitation equipment [10].

To achieve this objective, a first phase identified the stakeholders concerned by the ROBO-K device such as technical partners (BA Healthcare, CAE STIL ${ }^{2}$ ) or InvenSense ${ }^{3}$; clinical partners (the Physical Medicine and Rehabilitation Department (PMR) of the Rennes University Hospital, the Neurology Department of the Mutualist Centre for Re-education and Functional Rehabilitation of Kerpape) and end-users (patients and practitioners involved throughout the ROBO-K project). Then, the second stage of stakeholder analysis mobilized psychosocial skills focusing on the social acceptability of technologies [11]. These skills were used to anchor the innovation process on a co-construction activity with all the actors involved. Thus, the co-construction activity took into account the perceptions and opinions of all stakeholders of the ROBO-K project.

\section{Methodology: The robo-k project, a system co-constructed with all stakeholders}

\section{A psychosocial analysis framework to support the in- novation process}

In social psychology, the use of technology is considered to be the result of individual decision-making related to a behavioral intention (e.g. [12]). The latter is supposed to reflect people's attitudes towards innovation and can be influenced, for example, by their perception of - a) the utility of the innovative device to perform a given task; b) its usability or ease of use and c) the situation in which the technology is deployed (e.g. what others think of the technology used in the deployment situation...) [13]. These perceptions are studied at different points in the innovation process: before the design (i.e. a priori acceptability), then during the short-term manipulation (i.e. acceptance) and long-term manipulation (i.e. appropriation) of the innovative device (Figure 1) [11].

The longitudinal study of the representations generated by innovation is particularly important in professional environments. It participates in the definition of the individual or collective support needs for the diffusion of innovative materials (e.g. skills acquisition, organizational changes, etc.) $[14,15]$. This methodology (Figure 2) starts with an assessment

${ }^{1}$ Single Interministerial Fund.

Commissariat of Atomic Energy and Alternative Energies, Systems and Technology Integration Laboratories

Developing different types of sensors.

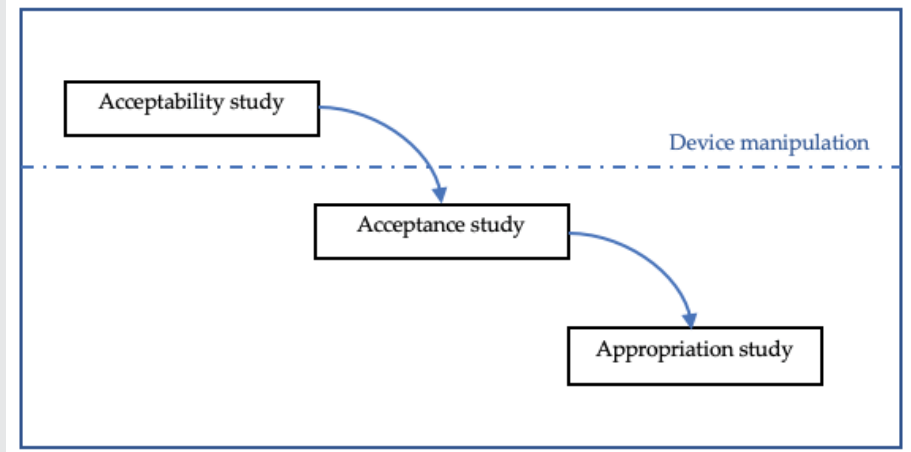

Figure 1: Social acceptability continuum.

of the existing situation and leads step by step to the design of a prototype.

\section{An implementation process involving stakeholders}

The design of the ROBO-K implementation process follows the analytical framework explained in section 2.1. It involved the active collaboration of the clinical partners as well as an association: APPROCHE ${ }^{4}$, and several simultaneous or successive studies (Figure 2). These studies require the application of mixed methods to access work reality: direct and indirect observations and quasi-experiments.

\section{Results of the co-construction robot activity}

The mobilization of potential or actual users during the different stages of development of the ROBO-K project (Figure 2), led to a co-constructed definition between the different stakeholders of the future robotic device (Figure 3).

Composed of two main elements - a holonomic mobile base and a suspension system that holds the patient in place while preventing him or her from sitting down - the gait rehabilitation robot presented above appears as:

1. An incremental (or integrative) innovation because this robotic equipment improves the therapeutic protocols usually applied by allowing early management of patients (i.e. gait preparation phase). The robot assists in the verticalization of patients (e.g. sit/stand work, standing static balance work). The robotic device can also be used to perform walking exercises (i.e. the phases of rehabilitation and then improvement of walking) according to different trajectories: half-turns, turns, etc. with or without obstacles and/or technical aids. It allows gait rehabilitation that is close to real situations in rehabilitation rooms, which is not the case of the robots already on the market at the time of the assessment of the existing situation (Figure 2). Indeed, the gait rehabilitation robots listed only allow straightline gait rehabilitation. They may include the use of orthoses to mobilize the lower limbs;

${ }^{4}$ Association for the promotion of new technologies for people with disabilities

Citation: Pichot N, Nadarajah K, Bonan I, Caverot G, Somat A, et al. (2021) Stakeholder involvement in the innovation process: An example in medical robotics, the ROBO-K project. Ann Robot Automation 5(1): 047-050. DOI: https://dx.doi.org/10.17352/ara.000014 


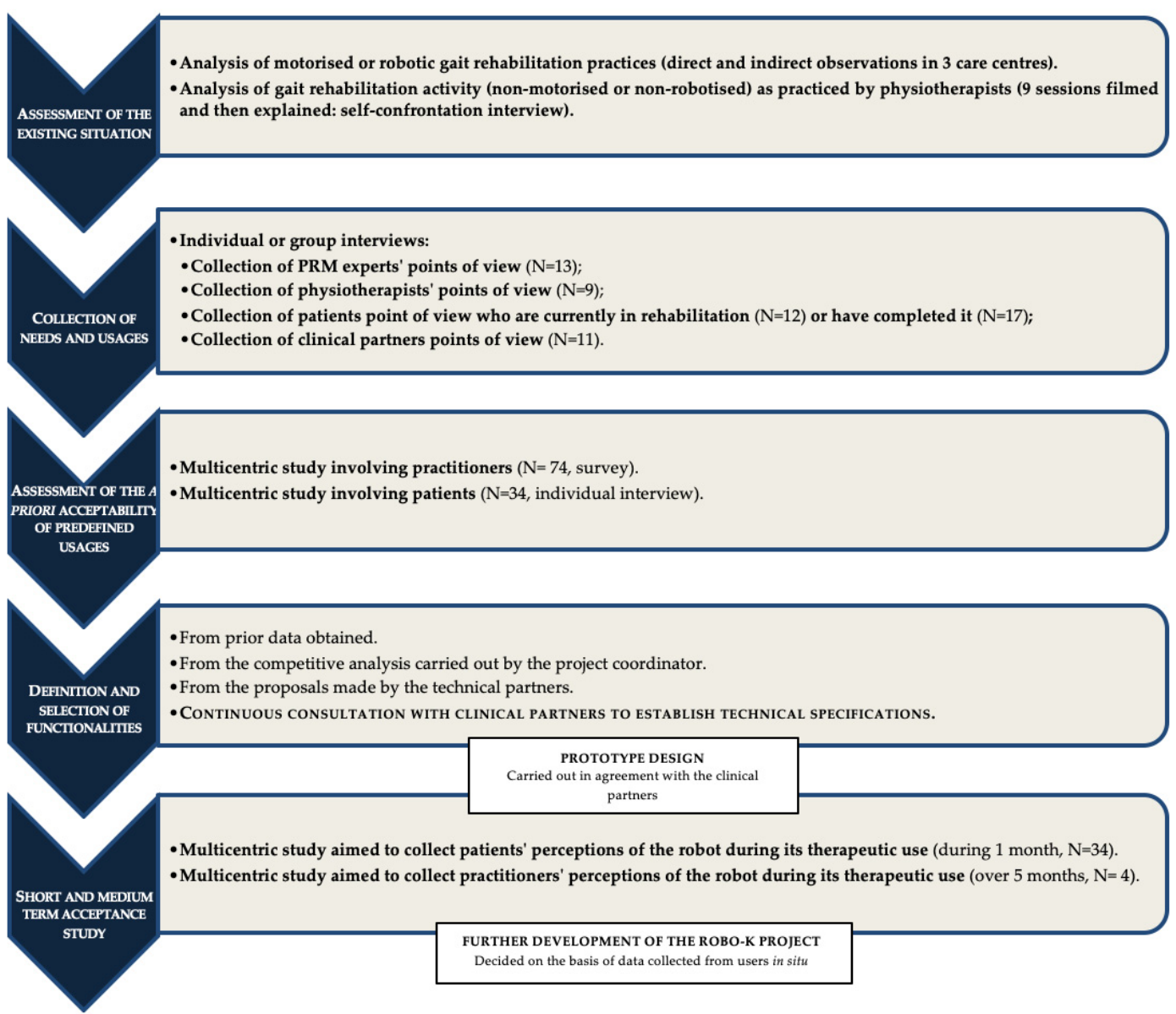

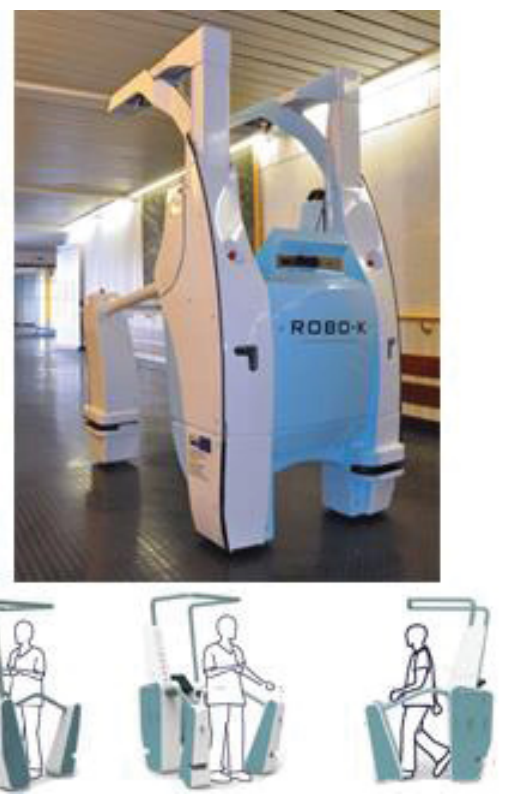

Figure 3: The gait rehabilitation robot (source: https://ba-healthcare.com/)

2. An innovation that respects ethical principles (e.g. nonstigmatisation of the patient) or the recommendations of medical bodies concerning gait rehabilitation practices (e.g. the continuous presence of the physiotherapist, the necessary adherence of the patient, the development of his autonomy, his safety during the rehabilitation session, the repetition of the exercises or the possibility to change them). The suspension and harness help to limit body weight and are therefore perceived a priori as useful by physiotherapists (Figure 2, the evaluation of the a priori acceptability). This result is also observed in the acceptance phase. The intention to use persists over time not only from the patients' but also from the professionals' point of view;

3. An innovation that respects the determinants and objectives of gait rehabilitation activity as practiced daily by physiotherapists (e.g. the progressiveness of the exercises or the need to adapt them to the patient's condition to avoid excessive fatigue or failure). The types of exercises that are possible (i.e. a priori acceptability, see Figure 2) or effective (i.e. short- and medium-term acceptance), facilitate the achievement of the rehabilitation goals;

4. An innovation that meets the requirements of the field, such as its configuration (e.g. the surface area of the rehabilitation rooms), the organization of the services (e.g. the planning of the treatments during the day), the duration (between 30 and 45 minutes depending on the center) and the course of the rehabilitation sessions (e.g. 
the time required for the transfer of the patients, the installation/disinstallation of the patients, the number and duration of the exercises). The elements resulting from the evaluation of the existing situation and the collection of needs or uses (Figure 2) helped to guide several aspects of the development of the robot (e.g. the size of the robot, the placement of the sensors for use in restricted and cluttered spaces with a physiotherapist nearby, and the autonomy of the batteries for daily use over two half-days in continuous ( 4 hours each)).

These characteristics of the robot are the result of all the work carried out with and by the end-users (Figure 2). Studying a priori perceptions of the robotic equipment (e.g. its usefulness, its perceived ease of use) helped to better anticipate its future use and to design appropriate training. Its introduction in rehabilitation rooms has been facilitated (in a test phase for 1 month for patients and 5 months for practitioners). The observations indicate that the robotic equipment tested supports existing care practices while generating new ones (e.g. related to dynamic balance work). However, they show the limits of the robotic system (e.g. its "robustness" with regard to continuous use within the services) and will thus contribute to its improvement. These observations mainly highlight its usefulness and emphasize the favorable attitude towards the robotic equipment. They show concern for usability.

\section{Conclusions}

Despite its contributions to the definition of the codesigned robot, the mobilization of end-users throughout the innovation process remains difficult to implement. The co-construction activity with all stakeholders takes time, substantial resources (human or financial), the application of specific methodologies (i.e. direct and indirect observation, quasi-experimentation), and, above all, makes the system more complex to meet the multiple requirements of all actors. In the ROBO-K project, four modes of use (e.g. remotely operated, programmed) were considered and 150 functionalities were established. Even if they were not all developed (either because they did not appear useful or usable, or because they required the removal of technological "locks" that were too important), they considerably increased the task of the technical partners. To overcome the problems of diffusion of technological innovations, it seems necessary to involve all stakeholders in the project. In the case of the ROBO-k project, focusing the design process on end-users and their activity also required the support of user associations (i.e. APPROCHE) and thus attests to the social character of technological innovations.

\section{Acknowledgments}

The realization of the ROBO-K project would not have been possible without the involvement of patients and practitioners. They are warmly thanked for their very important contribution as well as the APPROCHE association.

\section{References}

1. Bush V (1995) Science: The endless frontier. 1945. Reprint, North Stratford, $\mathrm{NH}$ : Ayer Co. Link: https://bit.ly/3GHQr1r
2. Godin B (2006) The Linear Model of Innovation: The Historical Construction of an Analytical Framework. Science Technology Human Values 31: 639-667. Link: https://bit.ly/3yn9jjn

3. Schmookler J (2013) Invention and Economic Growth [Internet]. Invention and Economic Growth. Harvard University Press. Link: https://bit.ly/31SITdm

4. Price WJ, Bass LW (2021) Scientific Research and the Innovative Process. Science. Link: https://bit.ly/31YoWBQ

5. Myers S, Marquis DG (1969) Foundation (U.S.) NS. Successful Industria Innovations: A Study of Factors Underlying Innovation in Selected Firms. National Science Foundation 146. Link: https://bit.ly/3pTXD3L

6. de Ana FJ, Umstead KA, Phillips GJ, Conner CP (2013) Value Driven Innovation in Medical Device Design: A Process for Balancing Stakeholder Voices. Ann Biomed Eng 41: 1811-1821. Link: https://bit.ly/3dNi4JU

7. Freeman RE (1984) Strategic Management: A Stakeholder Approach Cambridge University Press 294. Link: https://bit.ly/3yq2E7S

8. Chesbrough HW (2003) Open Innovation: The New Imperative for Creating and Profiting from Technology. Harvard Business Press 270. Link: https://bit.ly/3DUFOGC

9. Andrade AO, Pereira AA, Walter S, Almeida R, Loureiro R, et al. (2014) Bridging the gap between robotic technology and health care. Biomedical Signal Processing and Control 10: 65-78. Link: https://bit.ly/3oRECjf

10. Khomiakoff R, Czternatsy G, Vandromme L (2009) L'acceptation des aides techniques robotisées par la personne en situation de handicap moteur une approche psychologique. Journal de Réadaptation Médicale: Pratique et Formation en Médecine Physique et de Réadaptation 29: 51-58. Link: https://bit.ly/3pXkll6

11. Terrade F, Pasquier H, Reerinck-Boulanger J, Guingouain G, Somat A (2009) Social acceptability: How social determinant can influence analysis of technology system acceptability. Le travail humain 72: 383-395.

12. Ajzen I (1991) The Theory of Planned Behavior. Organ Behav Hum Dec 50: 179-211. Link: https://bit.ly/3IZ9iqX

13. Venkatesh V, Morris MG, Davis GB, Davis FD (2003) User Acceptance of Information Technology: Toward a Unified View. MIS Quarterly 27: 425-478. Link: https://bit.ly/3EWDDDT

14. Bigot O, Denancé V, Dufour F, Pasquier H, Pichot N, et al. (2014) De la conception à l'appropriation technologique : la conduite du changement par la conceptualisation dans l'action. Colloque tech'n use, Grenoble.

15. Pichot N, Quiguer S, Somat A (2018) Un cadre psychosocial d'intervention pour accompagner le développement et le déploiement d'une technologie nouvelle. Psychologie du Travail et des Organisations 24: 355-373. Link: https://bit.ly/3DQxjwf

Discover a bigger Impact and Visibility of your article publication with

Peertechz Publications

Highlights

* Signatory publisher of ORCID

* Signatory Publisher of DORA (San Francisco Declaration on Research Assessment)

* Articles archived in worlds' renowned service providers such as Portico, CNKI, AGRIS, TDNet, Base (Bielefeld University Library), CrossRef, Scilit, J-Gate etc.

* Journals indexed in ICMJE, SHERPA/ROMEO, Google Scholar etc.

* OAI-PMH (Open Archives Initiative Protocol for Metadata Harvesting)

Dedicated Editorial Board for every journa

Accurate and rapid peer-review process

* Increased citations of published articles through promotions

* Reduced timeline for article publication

Submit your articles and experience a new surge in publication services (https://www.peertechz.com/submission).

Citation: Pichot N, Nadarajah K, Bonan I, Caverot G, Somat A, et al. (2021) Stakeholder involvement in the innovation process: An example in medical robotics, the ROBO-K project. Ann Robot Automation 5(1): 047-050. DOI: https://dx.doi.org/10.17352/ara.000014 